\title{
Ethics and the COVID-19 Pandemic; A Clinician's Perspective
}

\section{Rajesh K Kulkarni and Aarti A Kinikar}

B J Government Medical College, Pune, India

Correspondence:

Rajesh K Kulkarni

B J Government Medical College, Pune, India

Email: docrajesh75@yahoo.com

DOI: $10.3126 /$ jnps.v40i2.29409

The COVID-19 pandemic has raised exigent medical, ethical and organisational challenges. While some excellent articles have been published about the ethical aspects of pandemics from a bioethicist's perspective, there is meager published literature on clinician's perspective. ${ }^{1}$ The issues important from a clinician's point of view are duty to treat, personal safety, safety of family, safety of colleagues, resource allocation, care for non COVID-19 patients and research.

The COVID-19 pandemic highlights the relevance of the question of health care workers duty to treat. Medical staff bore a significant brunt of the infection in China, Italy, Spain and the US. ${ }^{2}$ Being a clinician brings about a duty of beneficence to patients. Doctors have more obligations to help patients than non-doctors. Physicians are duty bound to treat patients who are victims of an infectious disease outbreak. This raises many pressing issues: what is an acceptable level of risk to the healthcare worker? When is the risk not reasonable, and who should decide? Do doctors have a right to refuse work if they do not receive adequate personal protective equipment?

The MCI 2002 Code of medical ethics regulation does not specify how doctors should act during a pandemic, although, it says a physician should not only be ever ready to respond to the calls of the sick and the injured, but should be mindful of the high character of his mission and the responsibility he discharges in the course of his professional duties. ${ }^{3}$ The American Medical Association (AMA) in its code of medical ethics adds a long term perspective : "Physicians should balance immediate benefits to individual patients with ability to care for patients in future." "For the AMA, the level of risk to be taken is left to the discretion of the individual, but it is noteworthy that the justification for not treating patients is one purely based on beneficence to future patients, not on the physician's other obligations to self or loved ones. The UK General Medical Council advises in Good Medical Practice : "Doctors must not refuse to treat patients because their medical condition may put the doctor at risk. The balance between protecting individual doctors and their families from harm, and ensuring patients are not put at unnecessary risk, is best addressed at local level, taking into account the principle that those who place themselves at additional risk should be supported in doing so and the risks and burdens minimised as far as possible." 5

Physicians' duty to care is not inexhaustible, as implied by the professional governance bodies, but determined by many factors including the physician's specialty (hence a dermatologist and an intensivist accept different levels of risk), the burdens and risk of harm to the clinician, the likely 
benefit of treatment to patients, and other competing social obligations a physician faces (e.g. as parent or a spouse). Malm et al. propose a contract-based consent: healthcare workers should voluntarily acknowledge the duty to treat during a pandemic and should be remunerated for that responsibility. ${ }^{6}$

Modern medicine relies on teamwork. Nurses, ancillary workers, ambulance drivers are all important part of the team. Often when resources are scarce, these team mates may not receive the same amount of attention from administrators (particularly with respect to personal protective equipment) when in fact they may be at greater risk of infection than senior staffs due to more frequent exposure.

It is well known that care for the non-pandemic diseases during a pandemic is affected. During the ongoing COVID-19 pandemic also there is published literature about cancer and other patient's care being affected. ${ }^{7}$ Strategies to minimise this need to be developed and this should be part of pandemic preparedness plan.

It is an ethical duty to carry out research during an epidemiological outbreak. Research during pandemic is important and impactful although there are certain obstacles to research e.g. the design and approval process of protocols may be slow, resources may be limited, and balancing patient care and research may be a huge challenge. The Ethics Committees and the health authorities need to apply the most rigorous standards to authorise research in accordance with the principles of justice, equity and solidarity.

\section{REFERENCES}

1. Mathur R. Ethics preparedness for infectious disease outbreaks research in India: A case for novel coronavirus disease 2019. Indian J Med Res. 2020;151(2):124-31. DOI:10.4103/ijmr.IJMR_463_20.

2. Ing EB, Xu QA, Salimi A, Torun N. Physician deaths from corona virus (COVID-19) disease, Occup Med-Oxford, kqaa088, DOI:10.1093/occmed/kqaa088

3. Indian Medical Council. Professional Conduct, Etiquette and ethics regulations [Internet] 2002. [Cited $9^{\text {th }}$ April 2020].

4. American Medical Association. Code of Medical Ethics [Internet] 2009. [Cited $9^{\text {th }}$ April 2020].

5. General Medical Council. Good medical practice. [Internet] 2013. [Cited $9^{\text {th }}$ April 2020].

6. Malm H, May T, Francis LP, Omer SB, Salmon DA, Hood R. Ethics, Pandemics, and the Duty to Treat. Am J Bioeth. 2008;8:4-19, DOI: 10.1080/15265160802317974

7. The LO. COVID-19: global consequences for oncology. Lancet Oncol. 2020;21(4):467. DOI:10.1016/ S1470-2045(20)30175-3 